\title{
Bisphenol-A contents in materials used in pediatric dentistry
}

\author{
Shoko Kaneko ${ }^{1)}$, Atsufumi Manabe ${ }^{2)}$, Satoshi Numazawa ${ }^{3)}$, Kazuo Itoh'), \\ Mitsuko Inoue ${ }^{1)}$, Takemi Yoshida ${ }^{3)}$, Hisashi Hisamitsu' ${ }^{2)}$ and Ryuji Sasa ${ }^{1)}$ \\ 1) Department of Pediatric Dentistry, Showa University, School of Dentistry \\ 2-1-1 Kitasenzoku, Ohta-ku, Tokyo 145-8515 JAPAN \\ 2) Department of Operative Dentistry, Showa University, School of Dentistry \\ 2-1-1 Kitasenzoku, Ohta-ku, Tokyo 145-8515 JAPAN \\ 3) Department of Biochemical Toxicology, Showa University, School of Pharmaceutical Sciences \\ 1-5-8 Hatanodai, Shinagawa-ku, Tokyo 142-8555 JAPAN
}

\begin{abstract}
Bisphenol-A (BPA) has been shown to be an endocrine disruptor in animals. We have previously demonstrated selective extraction of BPA from dental materials and its detection by gas chromatography-mass spectrometry. In the present study, this same procedure was employed for the detection of BPA in materials routinely used in pediatric dentistry-commercial resin composites, fissure sealants, compomers, and dentin bonding agents. In unpolymerized materials, significant BPA contamination was detected in 2 of 3 resin composites, 2 of 5 fissure sealants, and all bonding agents and intermediate resins tested. Moreover, in most cases, incubation of polymerized materials for $24 \mathrm{~h}$ resulted in release of BPA into phosphate-buffered saline. However, the highest level of BPA released $(89.5 \mathrm{ng} / \mathrm{g}$ polymerized material) was still far less than the reported lowest dose that produces endocrine disruption in experimental animals $(2 \mu \mathrm{g} / \mathrm{kg} / \mathrm{d})$.
\end{abstract}

Key words Bisphenol-A, Dental materials, Gas chromatography-mass spectrometry

\section{Introduction}

Resin composite was first synthesized by Bowen in 1962 by mixing bisphenol-A diglycidyl methacrylate (bis-GMA) with inorganic filler, and, today, it is the esthetic dental material of choice over metal restorations ${ }^{1)}$. However, this material has recently become the center of public attention on account of reports of leaking of components from the resin. One such leakable compound, identified as 2hydroxyethyl methacrylate (2-HEMA), has been shown to diffuse from both the bonding agent and the resin composite into dentin, and to produce contact dermatitis in experimental animals ${ }^{2,3}$. In addition to 2-HEMA, other monomers such as bisphenol-A (BPA), can also cause occupational contact dermatitis and 10-Methacryloxdecyl dihy-

Received on March 25, 2003

Accepted on September 8, 2003 drogen phosphate, used as a functional monomer, produces nebulous discoloration ${ }^{4,5)}$. Although such harmful effects of monomers in resin composite or dentin bonding agent have been reported, these materials are still needed in order to obtain complete marginal adaptation to the dentin of the cavity wall ${ }^{6-9)}$.

Synthetic non-steroidal substances, including dioxins, DDT, and BPA have been shown to exhibit endocrine-disrupting activity such as estrogen-like actions ${ }^{10)}$. Krishnan et al. found that BPA can be released from polycarbonate flasks during autoclaving ${ }^{11)}$. Later, vom Saal et al. demonstrated that administration of BPA significantly decreased efficacy of sperm production in rats by $20 \%{ }^{12}$. In the field of pediatric dentistry, Olea et al. showed bis-GMAbased sealant to cause xenoestrogenisity in vitro, and, using HPLC and gas chromatography-mass spectrometry (GC-MS), demonstrated that BPA can be released from the sealant ${ }^{13)}$. This report caused immense concern to parents worldwide, although 
Table 1 BPA contents in unpolymerized materials and leaked BPA amounts from polymerized materials

\begin{tabular}{|c|c|c|c|c|}
\hline Brand Name & Lot No. & Company & $\begin{array}{l}\text { BPA Contents* } \\
\quad(\mathrm{ng} / \mathrm{mg})\end{array}$ & $\begin{array}{l}\text { BPA Amounts** } \\
(\mathrm{ng} / \mathrm{g})\end{array}$ \\
\hline \multicolumn{5}{|l|}{ Resin Composites } \\
\hline Clearfil Photo SC & $0 \mathrm{O} 40$ & Kuraray (Osaka, Japan) & $\mathrm{UDL} * * *$ & $9.06 \pm 5.30 * * * *$ \\
\hline Palfique Estelite & 162 & Tokuyama (Tokyo, Japan) & UDL & $20.9 \pm 16.7$ \\
\hline Silux Plus & 7EA & 3M (St. Paul, U.S.A.) & $6.40 \pm 2.23$ & $89.5 \pm 59.7$ \\
\hline \multicolumn{5}{|l|}{ Fissure Sealants } \\
\hline Concise & 9ED & $3 \mathrm{M}$ & $15.4 \pm 1.12$ & $17.5 \pm 3.25$ \\
\hline Helioseal F & A15129 & Vivadent (Schaan, Lichtenstein) & UDL & $19.5 \pm 0.46$ \\
\hline Palfique Light Sealant & 416 & Tokuyama & UDL & $16.0 \pm 6.41$ \\
\hline Teeth Mate A & 0006 & Kuraray & $20.2 \pm 16.4$ & $55.7 \pm 17.5$ \\
\hline Teeth Mate F & 0009 & Kuraray & UDL & $10.9 \pm 5.30$ \\
\hline \multicolumn{5}{|l|}{ Compomers } \\
\hline Compoglass & 909088 & Vivadent & N.D. $* * * * *$ & $3.81 \pm 3.68$ \\
\hline Compoglass F & B00069 & Vivadent & N.D. & $5.70 \pm 2.47$ \\
\hline Dyract & 9609096 & Densply Detrey (Weybridge, UK) & N.D. & $9.89 \pm 7.70$ \\
\hline F2000 & $9 \mathrm{BC}$ & $3 \mathrm{M}$ & N.D. & UDL \\
\hline Geristore & 802201 & Den Mat (Santa Maria, U.S.A.) & N.D. & $55.7 \pm 29.2$ \\
\hline Hytac & CE0123 & ESPE (Oberbay, Germany) & N.D. & $3.26 \pm 3.00$ \\
\hline Ionosit Fil & 99220562 & DMG (Hamburg, Germany) & N.D. & $6.34 \pm 2.00$ \\
\hline Xeno & $312-05$ & Sankin (Tochigi, Japan) & N.D. & $4.33 \pm 3.53$ \\
\hline \multicolumn{5}{|l|}{ Bonding Agents } \\
\hline Clearfil Liner Bond II & 0099 & Kuraray & $4.80 \pm 0.30$ & N.D. \\
\hline Clearfil Liner Bond II $\Sigma$ & 289,389 & Kuraray & $2.39 \pm 0.52$ & N.D. \\
\hline Clearfil Photo Bond & 501 & Kuraray & $18.5 \pm 2.79$ & N.D. \\
\hline One Up Bond F & & Tokuyama & $2.50 \pm 1.84$ & N.D. \\
\hline \multicolumn{5}{|l|}{ Intermediate Resin } \\
\hline Single Bond & 7AK & $3 \mathrm{M}$ & $3.58 \pm 1.44$ & N.D. \\
\hline
\end{tabular}

*: BPA contents in unpolymerized dental materials, **: Leaked BPA amounts from polymerized dental materials into PBS during incubation, $* * *$ : Under detection limit $(<1 \mathrm{ng} / \mathrm{mg})$, ****: Data are expressed as mean \pm S.D. $(\mathrm{n}=3)$, *****: Not determined

other investigators argued that none of the tested sealants released detectable amounts of BPA. It is thus essential to clarify this matter and address these concerns. We have previously used GC-MS as a sensitive method to detect BPA in dental materials ${ }^{14)}$. By using this same procedure, the present study was designed to measure BPA levels in commercial resin composites, fissure sealants, compomers, and dentin bonding agents, all of which are commonly used in pediatric dentistry.

\section{Materials and methods}

\section{Materials}

The commercial materials used in this study were five fissure sealants, three resin composites, eight compomers and five dentin bonding agents including intermediate resins, and they are listed in Table 1. Base resins containing urethanedimethacrylate were excluded. BPA and 2-HEMA were supplied from Tokyo Kasei Kogyo (Tokyo, Japan) and Merck (Schuchardt, Germany), respectively. The bis-GMA and triethyleneglycol dimethacrylate (TEGDMA) were obtained from Shin-Nakamura Chemical (Wakayama, Japan). Deuterium-labeled BPA (D-BPA) was obtained from Aldrich Chemical Company (Milwaukee, U.S.A.). Sep-Pak Plus cartridges were obtained from Waters (Milford, U.S.A.). N,OBis(trimethylsilyl)trifluoroacetamide (BSTFA) with $1 \%$ trimethylchlorosilane (TMCS) was purchased 
from Pierce Chemical Company (Rockford, U.S.A.).

\section{Preparation of polymerization specimens}

Commercial unpolymerized materials (resin composites, compomers and fissure sealants) were irradiated in a cylindrical glass tube $(4 \mathrm{~mm}$ in diameter $\times 5 \mathrm{~mm}$ in height) with a visible light source for $60 \mathrm{sec}$. The polymerized samples were then carefully removed from the glass tube and incubated in $10 \mathrm{~m} l$ of phosphate buffered saline (PBS) at $37^{\circ} \mathrm{C}$ for $24 \mathrm{~h}$.

\section{Extraction of BPA from dental materials}

For detection of BPA in unpolymerized dental materials, a stock solution of each unpolymerized material was prepared at a concentration of $10 \mathrm{mg} / \mathrm{ml}$ in $100 \%$ methanol and placed in a light protected glass tube. After centrifugation (3000 rpm, $10 \mathrm{~min}$ ) of unpolymerized material to remove insoluble filler, a proportion $(100 \mu l)$ was transferred to $10 \mathrm{ml}$ of $40 \%$ methanol and applied to a Sep-Pak C18 cartridge that had been preconditioned with $100 \%$ methanol $(10 \mathrm{~m} l)$ followed by distilled water $(10 \mathrm{~m} l)$. When polymerized materials were tested, PBS extracts were directly applied onto the preconditioned cartridge. To quantify the BPA content, $50 \mathrm{ng}$ of D-BPA was added to the solution of dental materials before the extraction procedure as an internal standard. The cartridge was washed with $10 \mathrm{ml}$ of $40 \%$ methanol and eluted with $5 \mathrm{ml}$ of $70 \%$ methanol. The eluate was evaporated under a nitrogen stream at $40^{\circ} \mathrm{C}$ and dissolved in $100 \mu \mathrm{l}$ of a silylation reagent of $1 \%$ TMCS in BSTFA. The reaction was carried out at $60^{\circ} \mathrm{C}$ for $1 \mathrm{~h}$. After derivatization, the excess reagent was evaporated under a nitrogen stream and the residue was dissolved in $50 \mu l$ of ethyl acetate for GC-MS analysis.

\section{Gas chromatography-mass spectrometry analysis}

A proportion $(1 \mu l)$ of silylated extract from all dental materials tested was introduced into a GC-MS system (Hewlett Packard 5890A-5970B, Palo Alto, U.S.A.), equipped with an apolar GC capillary column HP-1 $(30 \mathrm{~m} \times 0.25 \mathrm{~mm} \phi, 0.25 \mu \mathrm{m}$ film thickness, Hewlett Packard) and a splitless injector. The temperature programming was as follows; $100^{\circ} \mathrm{C}(5 \mathrm{~min}), 100$ $300^{\circ} \mathrm{C}\left(20^{\circ} \mathrm{C} / \mathrm{min}\right), 300^{\circ} \mathrm{C}(5 \mathrm{~min})$. The temperature settings for the injector and a transfer line were $200^{\circ} \mathrm{C}$ and $300^{\circ} \mathrm{C}$, respectively. Electron-impact mass spectra were obtained at $70 \mathrm{eV}$ and reported as $\mathrm{m} / \mathrm{z}$.
Data was collected using a selective ion monitoring (SIM) mode to quantify the compound. Ions at $\mathrm{m} / \mathrm{z} 357$ and 368 were selected for SIM analysis of BPA and its deuterium derivative, respectively. The detection limit for BPA in the present system was $1 \mathrm{ng} / \mathrm{mg}$ in unpolymerized material, as reported previously.

\section{Results}

Levels of BPA detected in unpolymerized materials and released from polymerized materials into PBS during incubation are shown in Table 1 . In unpolymerized materials, we detected significant amounts of the BPA in 2 of 3 resin composites, 2 of 5 fissure sealants, and all bonding agents and intermediate resins tested. Levels of the BPA in these resins varied. Higher levels of BPA were observed in Concise, Teeth Mate A, and Clearfil Photo Bond, all of which contained more than $15 \mathrm{ng} / \mathrm{mg}$ unpolymerized material $(15 \mathrm{ppm})$. Though very low levels of BPA were observed in unpolymerized Clearfil Photo SC, Helioseal F, Palfique Light Sealant, and Teeth Mate $\mathrm{F}$, detectable leakage of BPA from these polymerized materials were found following incubation in PBS for $24 \mathrm{~h}$ (Table 1). These results indicate that polymerized materials release BPA during incubation. Such BPA leakage from polymerized materials was observed for all resin composites, fissure sealants, and compomers tested, except for F2000. Geristore compomer, which utilizes chemical polymerization methodology, showed a relatively high level of BPA leakage from the polymerized material. In resin composites, BPA contents in unpolymerized materials were seen to correlate with BPA leakage from polymerized materials. However, there was no relationship between these two parameters in the case of fissure sealants.

\section{Discussion}

The adhesion of composite resin to dentin is of critical importance in the restorative field. Indeed, the ability of resins to bond to dentine obviates the need to undercut cavities, as required for amalgam restoration placement for example, so avoiding unnecessary destruction of dentin and ultimately prolonging the life of the tooth ${ }^{14-16)}$. Although metalbased restorations have been widely used in the past, ceramics and composite resins are now applied not only to anterior teeth but also to molars ${ }^{17)}$. 
Furthermore, pediatric dentists tend to use resin composites when the devitalized teeth is covered with jacket crowns. Unfortunately, there has been recent concern that plastic-based dental materials induce endocrine disrupting actions, through the release of BPA used as a starting material for bis-GMA synthesis and therefore contaminates unpolymerized materials ${ }^{18)}$. These anxieties have spread to our pediatric dental patients and their families, and it is essential that we are able to address these concerns. The present study was designed to determine the BPA content of composite resins, fissure sealants, compomers, and bonding agents.

Results obtained from this study revealed that BPA was released from all polymerized materials tested except F2000 compomer. The highest level of BPA released during the $24 \mathrm{~h}$ incubation was in the order of $90 \mathrm{ng} / \mathrm{g}$ of polymerized material. Nagel et $a l$. reported that repeated doses of $2 \mu \mathrm{g} / \mathrm{kg} /$ day of BPA to pregnant mice resulted in an increase in the size of the prostate and preputial glands and a decrease in the size of the epidiymides in their male offspring ${ }^{19)}$. Although the BPA levels detected in the current study were far less than these reported doses that produce endocrine disruption in animals, there is still potential concern in the dental office, particularly in the case of bonding agents, which are used unpolymerized.

To prevent leakage of BPA from resin-based materials, complete polymerization is essential. It is also important to wait for apparent hardening of the material and to grind the resin surface, particularly in the case of the chemical polymerization-type resin, where polymerization of the surface is inhibited by oxygen. Moreover, when using optical polymerization-type resin in deep cavities it is necessary to laminate the polymerization since visible light can only reach a distance of some $2 \mathrm{~mm}$ into the material. Without laminating, it is likely that unpolymerized material will remain. A further concern is the leakage of bonding agent, containing high levels of monomer, through the crevice between the rubber dam and gingiva. This could induce a delayed-type allergic reaction in the oral tissues, in addition to endocrine-disrupting actions. In short, it is essential to pay careful attention to the manipulation of dental materials that contain BPA and, in some cases, glass ionomer-type materials may be a preferable choice.

In conclusion, the present study reports the levels of BPA in unpolymerized materials and those leaked from polymerized materials using 21 commerciallyavailable brands of resin composite, fissure sealant, compomer, bonding agent, and intermediate resin. While it is apparent that BPA is released by dental materials commonly used in dental practice, the results of this study demonstrate that levels are significantly lower than those reported to have detrimental effects.

\section{References}

1) Bowen, R.L.: Dental filling materials comprising vinyl silane treated fused silica and a binder consisting of the reaction product of bisphenol and glycidyl acrylate. US Patent \#3,066,112: 1962.

2) Clemmensen, S.: Sensitizing potential of 2-hydroxyethylmethacrylate. Contact Dematitis 12: 203-208, 1985.

3) Katsuno, K., Manabe, A., Itoh, K., Nakamura, Y., Wakumoto, S., Hisamitsu, H. and Yoshida, T.: Contact dermatitis caused by 2-HEMA and GM dentin primer solutions applied to guinea pigs and humans. Dent mater J 15: 22-30, 1996.

4) Katsuno, K., Manabe, A., Itoh, K., Hisamitsu, H., Wakumoto, S., Nakayama, S. and Yoshida, T.: A delayed hypersensitivity reaction to dentine primer in the guinea-pig. J Dent 23: 295-299, 1995.

5) Manabe, A., Katsuno, K., Kurihara, A., Itoh, K., Hisamitsu, H., Wakumoto, S., Iijima, M. and Yoshida, T.: Adverse effect of dentine bonding agent on the oral mucosa of guinea pigs. J Oral Rehab 28: 88-94, 2001.

6) Chigira, H., Itoh, K., Tachikawa, T., Wakumoto, S. and Hisamitsu, H.: Bonding efficacy and interfacial microstructure between resin and dentine primed with glyceryl methacrylate. J Dent 26: 157-163, 1998.

7) Manabe, A., Itoh, K., Tani, C., Hisamitsu, H. and Wakumoto, S.: Effect of functional monomer in commercial dentin bonding agents use of an experimental dentin bonding system. Dent Mater J 18: 116-123, 1999.

8) Manabe, A., Itoh, K. and Wakumoto, S.: The optimum combination of dentin bonding systems. Dent Mater J 7: 145-147, 1991.

9) Chigira, H., Itoh, K. and Wakumoto, S.: Marginal adaptation of nine commercial intermediate resins. Dent Mater J 7: 103-106, 1991.

10) Brotons, J.A., Olea-Serrano, M.F., Villalobos, M., Pedraza, V. and Olea, N.: Xenoestrogens released from lacquer coatings in food cans. Environ Health Perspect 103: 608-612, 1995.

11) Krishnan, A.V., Stathis, P., Permuth, S.F., Tokes, L. and Feldman, D.: Bisphenol-A: An estrogenic substance is released from polycarbonate flasks during autoclaving. Endocrinology 132: 2279-2286, 1993. 
12) vom Saal, F.S., Cooke, P.S., Buchanan, D.L., Palanza, P., Thayer, K.A., Nagel, S.C., Parmigini, S. and Welshons, W.V.: A physiologically based approach to the study of bisphenol A and other estrogenic chemicals on the size of reproductive organs, daily sperm production, and behavior. Toxicol Ind Health 14: 239-260, 1998.

13) Olea, N., Pulgar, R., Pérez, P., Serrano, F.O., Rivas, A., Fertrell, A.N., Pedraza, V., Soto, A.M. and Sonnenschein, C.: Estrogenicity of resin-based composites and sealants used in dentistry. Environ Health Perspect 104: 298-305, 1996.

14) Torii, Y., Iwami, Y., Kato, R., Iwazato, T., Torii, M. and Tsuchitani, Y.: Bonding ability of light cured composite resin to enamel and dentin promoted by various bonding systems-microleakage and bond strength studies. J Osaka Univ Dent Sch 30: 72-77, 1990.

15) Pereira, P.N., Inokoshi, S., Yamada, T. and Tagami, J.: Microhardness of in vitro caries inhibition zone adjacent to convention and resin-modified glass ionomer cements. Dent Mater J 26: 505-510, 1998.

16) Burrow, M.F., Tagami, J., Negishi, T., Nikaido, T. and Hosoda, H.: Early tensile bond strengths of several enamel and dentin bonding systems. J Dent Res 73: 522-528, 1994.

17) Okada, T., Shinya, A. and Yokozuka, S.: Effects of load and loading time on fracture toughness with indentation method. Shigaku 78: 460-486, 1990.

18) Manabe, A., Kaneko, S., Numazawa, S., Itoh, K., Inoue, M., Hisamitsu, H., Sasa, R. and Yoshida, T.: Detection of Bisphenol-A in dental materials by gas chromatography-mass spectrometry. Dent Mater $J$ 19: 75-86, 2000

19) Nagel, S.C., vom Saal, F.S., Thayer, K.A., Dhar, M.C., Boechler, M. and Welshons, W.V.: Relative binding affinity-serum modified access (RBA-SMA) assay predicts the relative in vivo bioactivity of the xenoestrogens bisphenol A and octylphenol. Environ Health Perspect 105: 70-76, 1997. 